\title{
Sperm collection in Black-legged Kittiwakes and characterization of sperm velocity and morphology
}

\author{
Ségolène Humann-Guilleminot ${ }^{1 *}$, Pierre Blévin ${ }^{2}$, Antonin Azou-Barré1 , Agathe Yacoumas ${ }^{1}$, \\ Geir Wing Gabrielsen ${ }^{3}$, Olivier Chaste ${ }^{2+}$ and Fabrice Helfenstein ${ }^{1+}{ }^{+}$
}

\begin{abstract}
Background: Collecting and studying live sperm is central to many important fields of biology. Yet, a simple method to collect live sperm is lacking in wild seabird species. Here, we describe a non-invasive method to collect viable sperm samples based on a simple massage technique applied to male Black-legged Kittiwakes (Rissa tridactyla).

Methods: We studied a colony breeding at Kongsfjorden, Svalbard and successfully obtained sperm samples from 32 males. With a subset of samples ( $n=12$ males), we compared the suitability of several extenders $(0.9 \% \mathrm{NaCl}, \mathrm{PBS}$, Earle's balance salt solution, Dulbecco's modified Eagle medium) in maintaining sperm alive long enough for analyses. With another 18 ejaculates, we conducted computer assisted sperm analyses using the CASA plugin for ImageJ. We provide details about the settings to be used for such analyses. Lastly, droplets from 20 ejaculates were smeared on glass slides and preserved with formalin to characterize sperm morphology in terms of total sperm length, sperm head length, midpiece length and flagellum length, and percentage of abnormal sperm.

Results: With this method and under field conditions, we were able to obtain sufficient amounts of live sperm to assess traits related to sperm quality (e.g. sperm morphology, percentage of motile sperm, sperm velocity). We found that two extenders, Earle's balanced salt solution and Dulbecco modified Eagle's medium, yielded similarly good results. Additionally, we investigated whether specific behaviours were associated with successful sperm collection and whether sperm collection success depended on how long before laying sperm collection was attempted. Finally, we provide mean values for sperm morphology, sperm swimming ability and percentage of motile sperm, which may prove useful for future comparative analyses, and we report high levels of sperm abnormality and within-ejaculate variation in sperm morphology.
\end{abstract}

Conclusions: We discuss the high percentage of abnormal sperm and high within-ejaculate variation in sperm morphology in light of sperm competition theory and conclude that these figures are likely due to relaxed post-copulatory sexual selection, kittiwakes being strictly monogamous. Finally, we suggest that this method could be applied to other seabird species sharing similar ecology.

Keywords: Black-legged Kittiwakes, Sperm, Spermatozoa, Semen collection, Non-invasive method, Larids, Sperm velocity, Sperm morphology, Abnormal sperm

*Correspondence: segolene.humann@gmail.com

†Olivier Chastel and Fabrice Helfenstein: Shared senior authorship

1 Laboratory of Evolutionary Ecophysiology, Institute of Biology, University

of Neuchatel, Rue Emile-Argand 11, 2000 Neuchatel, Switzerland

Full list of author information is available at the end of the article 


\section{Background}

There has been a long-time interest in the biology of spermatozoa, undeniably elicited by their large interspecific diversity and their role in transmitting genetic information to the next generation. The vast diversification of sperm morphology was produced in response to the selective pressures imposed by their specific fertilizing environment, i.e. the surrounding environment in external fertilizers and the female reproductive tract in internal fertilizers (Franzén 1956; Alberti 1990; Jamieson 2007). In addition to this selection, post-copulatory sexual selection [sperm competition (Parker 1970) and cryptic female choice (Thornhill 1983; Eberhard 1996)] is also known to drive the evolution of sperm morphology and function (i.e. capacity to reach, penetrate and fertilize the ovum; Fitzpatrick and Lüpold 2014) across and within species. Clearly, strong selective forces act on sperm cells to optimize their fertilizing ability, and the study of the evolutionary patterns and processes underlying inter- and intra-specific variation in sperm quality has elicited much interest in the last two decades (Birkhead and Pizzari 2002; Pitnick et al. 2009; Fitzpatrick and Lüpold 2014; Reinhardt et al. 2015).

Sperm quality is also influenced by environmental factors, like nutrition (Bronson 1989), diseases (Nicopoullos et al. 2004) or pollutants (Jurewicz et al. 2009). For example in humans, there is ample evidence that environmental pollutants affect sperm quality and thus male fertility. Indeed, pesticides, air pollutants and others environmental chemicals have all been shown to decrease sperm quality in human beings (Swan et al. 2003; Sharpe 2010; Lafuente et al. 2016). The impact of pollutants on sperm quality in domestic, livestock or captive animals is also well known (e.g. Hatef et al. 2013; Komsky-Elbaz and Roth 2017), and studies in free-ranging animals would now be timely.

Seabirds are popular models for research in ecology and evolutionary biology because they can be easily captured, individually marked as chicks and adults, equipped with various loggers (Wilson et al. 2007) which allows experimental field studies (e.g. Goutte et al. 2011; Merkling et al. 2017). Additionally, due to their position at the top of the food chain, long-lived seabirds often bio-accumulate many contaminants via food intake and are thus ideal models in eco-toxicological studies (Elliott and Elliott 2013). Surprisingly, although seabirds would be suitable models to study ecological, evolutionary and toxicological questions in relation to sperm quality, no such study exists. The obvious reason being that, with the exception of captive Magellanic Penguins (Spheniscus magellanicus) (O'Brien et al. 1999), no method for collecting sperm in seabirds has been described so far, and applying methods originally described for poultry and passerine birds is not as easy as one would intuitively think.

The purpose of this study was to collect live sperm, for the first time, using a non-invasive method in a common seabird with a wide geographical distribution, the Black-legged Kittiwake (Rissa tridactyla). In this paper, we also provide information about suitable sperm extenders and relevant timing in relation to the breeding phenology of the kittiwakes, as well as a video showing how the collection was done (Additional file 1: Video S1). Finally, we report values for sperm morphology, percentage of abnormal sperm, and sperm swimming traits, which are valuable information for comparative studies. This method to collect sperm is adapted to field conditions, and we believe that it could be easily adapted to other seabird species with similar ecology (e.g. laridae or alcidae). Because it does not require killing the birds, we believe that this method will appeal to scientists interested in sperm biology in seabirds, and working in a variety of disciplines from veterinary sciences to conservation biology, evolutionary biology and ecotoxicology.

\section{Methods \\ Model species, study site and bird capture}

Black-legged Kittiwakes are pelagic seabirds, which breed in very dense colonies and lay 1-3 eggs (Coulson 2011). They are monogamous, do not engage in extra-pair copulations and exhibit low copulation rates with an average of 14 copulations during the 23 days that precede the laying of the clutch (Helfenstein et al. 2004).

Fieldwork was carried out from May 24th to June 11th 2016, in a colony of Black-legged Kittiwakes at Kongsfjorden $\left(78^{\circ} 54^{\prime} \mathrm{N} ; 12^{\circ} 13^{\prime} \mathrm{E}\right)$, Svalbard. We caught a total of 50 males directly on their nest using a nylon noose tied at the end of a 5-m fishing rod, during the pre-laying period (i.e. during nest building and copulation). Immediately after capture, birds were first blood sampled for hormones and contaminants. Carotenoid-based ornaments coloration, and biometry (body mass, tarsus length, wing length, skull length) were then measured, which delayed sperm collection for at least $30 \mathrm{~min}$ after bird capture. Kittiwakes were individually marked with metal rings and PVC plastic bands engraved with a three-digit code and fixed to the bird's tarsus for identification from a distance.

In order to save time by targetting males who would give us good ejaculates, we noted the behaviour of the male and the female just before capture. Behaviours were categorized as: no specific behaviour observed, female begging for food, male about to mount the female, copulation occurred maximum $1 \mathrm{~h}$ ago. 


\section{Laying date and temporal optimum for sperm collection}

Before release, kittiwakes were marked with spots of dye on the forehead in order to identify individuals and thereby their nest. We checked the nest content of sampled birds every two days to monitor breeding stage (at least one egg is laid or no egg laid) and egg-laying date using a mirror at the end of an 8-m fishing rod. We estimated the most successful time to collect sperm relative to the laying of the first egg of a given pair by plotting a probability of success (number of successful sperm collection divided by the total number of attempts per day) against the number of days before laying. Sperm collection was considered successful when the ejaculate contained at least 10 motile spermatozoa.

\section{Sperm collection}

Sperm samples were obtained by firmly massaging the lower back and the base of the tail of the male. For easier handling, we recommend to keep the bird's head in a fabric bag and to maintain the bird on your thighs and on its belly using your forearm, keeping your hands free for massaging and collecting sperm (see Additional file 1: Video S1). In the field, we observed that males wagged their tail during mating, and this observation prompted us to massage the base of the tail while moving it laterally for ca. $5 \mathrm{~s}$. After this massage, the handler lifted the tail, cleared the feathers around the cloaca and gently squeezed the cloaca with two fingers with one hand, while using the other hand to collect the ejaculate directly in a non-heparinized $75 \mu \mathrm{L}$ capillary with $5 \mu \mathrm{L}$ graduation (VWR, reference 612-3417). The capillary was placed on the top of the cloaca, closest to the tail (Fig. 1). Males made a series of cloacal contractions before extruding a translucent liquid, which was verified to be sperm under the microscope (see Additional file 2: Video S2). We always avoided pressing too deep under the cloaca or on the belly to avoid contamination by faecal matter.

\section{Assessing sperm survival}

For a subset of the males $(n=12)$, we immediately started a stopwatch after the extrusion of an ejaculate in a capillary to assess the survival of spermatozoa. Sperm samples were divided in two $5 \mu \mathrm{L}$ aliquots and each aliquot was pipetted into $5 \mu \mathrm{L}$ of either pre-warmed PBS $(1 \times$ phosphate-buffered saline), physiological saline $(0.9 \% \mathrm{NaCl})$, DMEM (Dulbecco's modified Eagle medium, $4500 \mathrm{mg}$ glucose/L, $110 \mathrm{mg} / \mathrm{L}$ sodium pyruvate and L-glutamine), Earle's balanced salt solution (EBSS) semen extender (including HAS, pyruvate, Hepes, Phenol red, sodiumbicabonate and Gentamicin $10 \mu \mathrm{g} / \mathrm{mL}$, SpermWash ${ }^{\circledR}$; Cryos, Aarhus, Denmark) or left undiluted. Three $\mu \mathrm{L}$ of

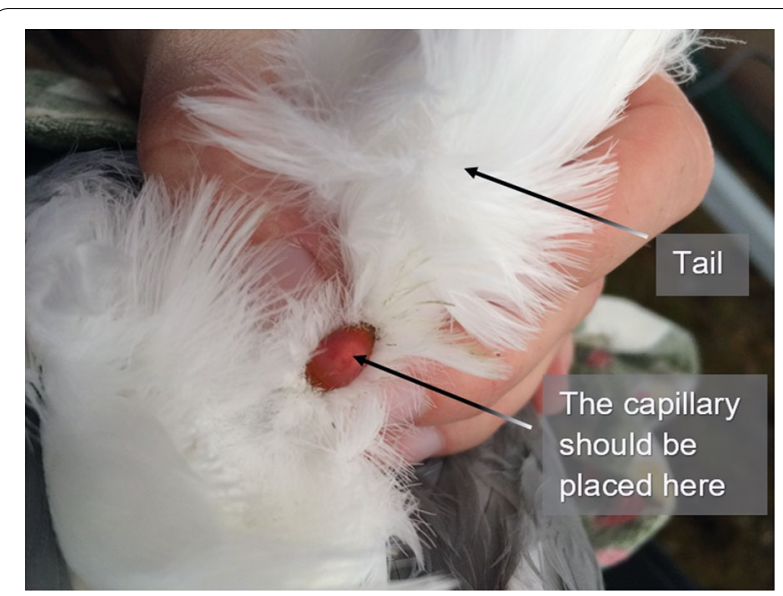

Fig. 1 Picture of a kittiwake's cloaca showing where to apply the capillary to collect the ejaculate

the mix sperm-extender or undiluted sperm were transferred into a 20- $\mu \mathrm{m}$ deep chamber slide (Leja Products B.V., The Netherlands), and the two swimming chambers were continuously visually inspected using an Olympus BX43 microscope (Olympus Co., Japan) with a $10 \times$ objective under negative phase contrast (position Ph3 of the annular phase ring). We maintained the temperature of the mix sperm-extender or undiluted sperm at $40{ }^{\circ} \mathrm{C}$ (the body temperature of adult kittiwakes ranges between 39.8 and $40.3{ }^{\circ} \mathrm{C}$; Barrett 1978; Brent et al. 1983) using a heating glass plate (MATS-U55S, Olympus Co., Japan) fitted to the microscope stage. Sperm survival was estimated as the time elapsed from the ejaculation until all spermatozoa were immotile.

\section{Assessment of percentage of motile sperm, sperm swimming ability and sperm morphology}

For another subset of males $(n=18)$, we immediately started a stopwatch after the extrusion of an ejaculate in a capillary and pipetted $5 \mu \mathrm{L}$ of semen into $5 \mu \mathrm{L}$ of DMEM. Three $\mu \mathrm{L}$ of this mix were transferred into a $20-\mu \mathrm{m}$ deep chamber slide (Leja Products B.V., The Netherlands). Sperm swimming ability was monitored using a Toshiba CMOS HD camera (TOSHIBA Corporation, Japan) mounted on an Olympus BX43 microscope (Olympus Co., Japan) with a $10 \times$ objective under negative phase contrast (position $\mathrm{Ph} 3$ of the annular phase ring). We maintained the temperature of the mix spermextender or undiluted sperm at $40^{\circ} \mathrm{C}$ (the body temperature of adult kittiwakes ranges between 39.8 and $40.3{ }^{\circ} \mathrm{C}$; Barrett 1978; Brent et al. 1983) using a heating glass plate (MATS-U55S, Olympus Co., Japan) fitted to the microscope stage. We recorded 5-s videos on four to five different fields to maximize the number of tracked spermatozoa. Changing fields to make several short videos of 
the same sperm sample was possible because spermatozoa proved to be able to remain motile over $40 \mathrm{~min}$. From the videos, we used the computer-assisted sperm analysis (CASA) plugin (Wilson-Leedy and Ingermann 2007) for ImageJ (Schneider et al. 2012) to assess the mean values for seven traits related to sperm swimming ability: VCL (curvilinear velocity, total distance travelled, $\mu \mathrm{m} / \mathrm{s}$ ), VAP (average path velocity, smoothed path using roaming average, $\mu \mathrm{m} / \mathrm{s}$ ), VSL (straight line velocity, distance from origin to end point, $\mu \mathrm{m} / \mathrm{s}$ ), linearity (LIN: VSL/ VAP, path curvature), wobble (WOB: VAP/VCL, side to side movement of the sperm head, also described as the oscillation of the actual trajectory about its average path), BCF (beat cross frequency, the frequency at which VCL crosses VAP, Hz), and progression (PROG: average distance from origin on the average path during all frames analysed). The CASA also assessed the percentage of motile sperm. Our videos were $1280 \times 720$ in resolution with 25 frames/s. Videos were imported into ImageJ as image stacks and converted to 8-bit images. The "threshold" function was used to discard particles smaller than a sperm cell and create adequate contrast with black sperm cells against a white background. The CASA settings were set as follows: minimum and maximum sperm size were 30 and 150 pixels; search radius (maximal distance in pixels between two frames for moving sperm) was 25 pixels; Low VAP was set to $5 \mu \mathrm{m} / \mathrm{s}$; the maximum percentage of path with low VAP between frames was $90 \%$ and the maximum percentage of path with null VAP was $10 \%$; these last three conditions discarded sperm, which do not show regular motion (sperm stuck or slowed down due to particles or collisions); when examining all the trajectories for a given sample, VCL and VAP always showed a bimodal distribution with a cut-off around $20 \mu \mathrm{m} / \mathrm{s}$. Therefore, sperm with VAP $<20 \mu \mathrm{m} / \mathrm{s}$ and VCL $<20 \mu \mathrm{m} / \mathrm{s}$ were assumed to be immotile and moved by drift. These estimates were based on $134 \pm 121$ sperm tracks (mean $\pm S D$; minimum: 20; maximum: 463) per ejaculate.

A small droplet from the ejaculate was immediately smeared with $10 \%$ formalin (1:9 v:v; i.e. $4 \%$ formaldehyde) on a glass slide. From each slide, we took photos of ten intact sperm cells using the Nikon ACT-1 v2.70 software (Nikon Corporation, Japan) with a Nikon DFC7000T camera (Nikon Corporation, Japan) mounted on a Leica DMR microscope (Leica Microsystems GmbH,
Germany) at $400 \times$ magnification and phase contrast 2 . Seven to 16 sperm cells (mean \pm SE: $10.1 \pm 0.5$ ) were measured for head, midpiece, flagellum and total length. Additionally, each cell was independently measured twice to assess the amount of variance due to measurement error using random models (Helfenstein et al. 2010). We used a re-sampling procedure to verify that measuring ten sperm cells accurately estimates male means, amongmale variation and within-ejaculate variation in total sperm length and length of sperm components (Additional file 3: Fig. S1, S2; Additional file 4: Supplementary dataset). The percentage of measurement error was $4.7 \%$ for head length, $12.5 \%$ for midpiece length, $1.3 \%$ for flagellum length, and $0.2 \%$ for total length. The average coefficient of variation $[(\mathrm{SD} /$ mean $) \times 100]$ for the two measures of the same sperm was $2.5 \%$ for head length, $5.2 \%$ for midpiece length, $1.1 \%$ for flagellum length, and $0.6 \%$ for total length. For further analyses the two measures per spermatozoon were averaged.

We estimated the variability in sperm morphology among males by computing an unbiased estimate of among-male coefficient of variation $\left(\mathrm{CV}_{\mathrm{am}}\right)$ using the formula adjusted for small sample sizes (Sokal and Rohlf 1995) based on average sperm measures for each individual. Then, we estimated the percentage of withinejaculate variance relative to the total variance (within ejaculates + among males/ejaculates) using random models (Helfenstein et al. 2010). Finally, we computed an unbiased within-ejaculate coefficient of variation $\left(\mathrm{CV}_{\text {we }}\right)$ by first calculating an unbiased $\mathrm{CV}$ for each male, then averaging the CVs of all individuals (Laskemoen et al. 2007)

Sperm smears were also used to assess the percentage of abnormal sperm for 19 ejaculates based on 50 spermatozoa per slide. Spermatozoa were classified as morphologically normal, with abnormal head (no head, S-shaped head, bended head, no acrosome, burst head), with abnormal midpiece (no midpiece, broken midpiece) or with abnormal flagellum (no flagellum, broken flagellum, folded flagellum, flagellum with $90^{\circ}$ angle, coiled flagellum, double flagellum, split flagellum) (Fig. 2).

\section{Statistics}

We investigated whether the date at which a male was trapped relative to the laying of the first egg in the focal nest influenced our success to obtain a spermic ejaculate

(See figure on next page.)

Fig. 2 Pictures of spermatozoa (400x magnification and phase contrast 2) showing: normal sperm (a); a sperm with S-shaped head (b); a head-less sperm (c, d); a sperm with burst head (e); a double-headed sperm (f); a sperm with bended head (g); a sperm with no acrosome (h); a sperm with abnormally long acrosome (i); a sperm with $90^{\circ}$-angle midpiece (j); a double-flagellated sperm (k); a sperm with split flagellum (I); a sperm with broken flagellum (m); a sperm with $90^{\circ}$-angle flagellum (n); and a sperm with coiled flagellum (o) 


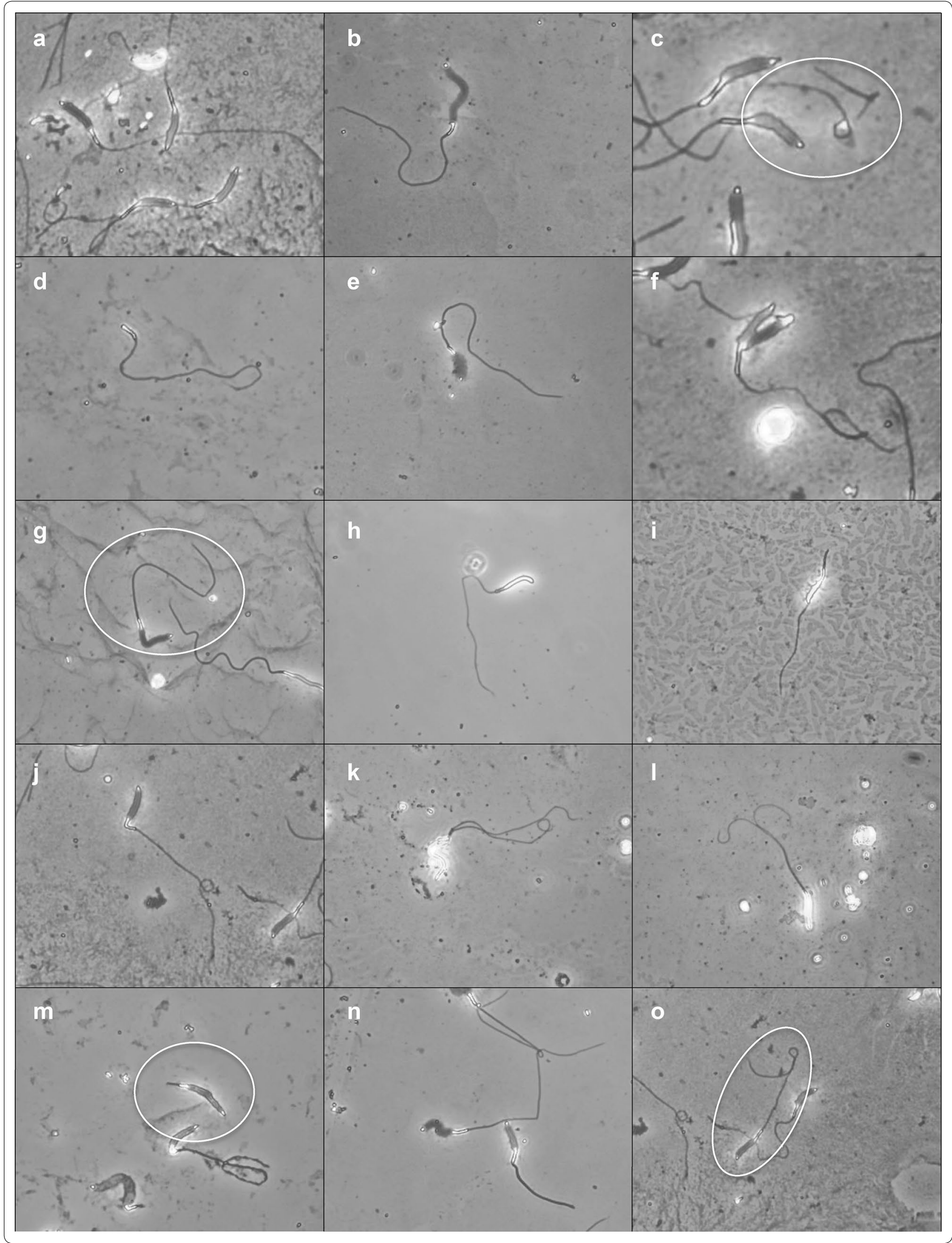


using a generalized linear model with quasibinomial distribution and logit link function and with number of success/number of attempts as the dependent variable and time relative to egglaying as the explanatory factor.

We tested for an association between sperm collection success and the behaviour of the pair immediately before the male was captured using a Fisher's exact test for $2 \times 4$ contingency tables.

Each sperm sample was tested for sperm survival in two conditions (either two different sperm extenders or one sperm extender and undiluted sperm; Table 1). We compared the effect of the various buffers on sperm survival using a Wilcoxon's signed-ranks test for paired samples. To run this test, and because our sample size is modest, we compared sperm survival of a given ejaculate in a given condition (undiluted sperm or sperm diluted in one of our four different extenders) against sperm survival of the same ejaculate in any other condition.

\section{Results}

All trapped individuals were massaged to collect sperm (50 individuals for 85 attempts, some males were trapped twice). All the birds responded to our stimulation and extruded a translucent fluid. This fluid contained spermatozoa in $33 \%$ of the cases (28 ejaculates with spermatozoa over 85 attempts). When sperm collection was succesful, we always obtained between 5 and $10 \mu \mathrm{L}$ of sperm per sample (based on capillary graduations). We used sperm samples of at least $10 \mu \mathrm{L}$ to test the sperm extenders. Thus, only a subsample of all ejaculates $(n=19$ from 12 individuals) were used to investigate the effect of the sperm extenders on sperm survival.

\section{Temporal optimum for sperm collection and relation to bird behaviour}

We collected ejaculates between 0 and 25 days before the first egg was laid in the nest of the focal bird. We could check the nest content of only 20 sampled birds out of the 25 which gave us sperm samples. Figure 3

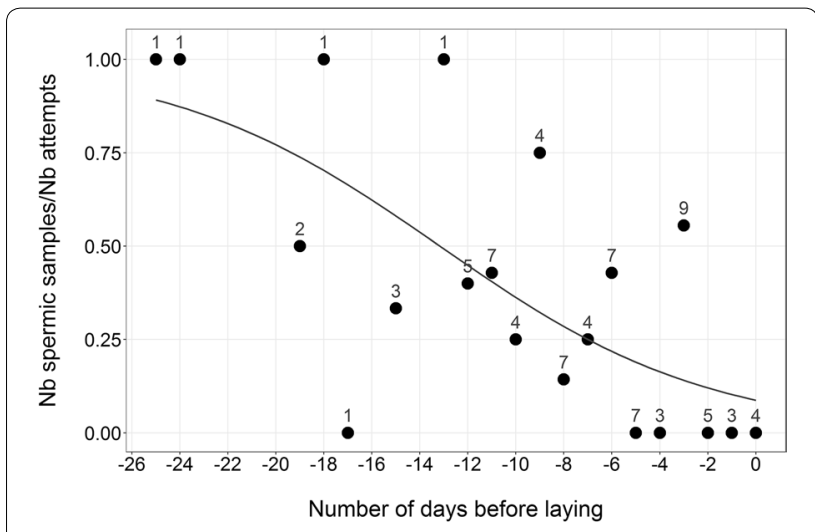

Fig. 3 Proportion of successful sperm collection (numbers of successful attempts divided by the total number of attempts) according to the number of days before laying. The numbers above the dots indicate the number of attempts made on a given day

shows a plot of sperm collection success according to number of days before laying. First, it shows that we trapped only a few birds $(n=6)$ in the period between 25 and 16 days before the laying of the first egg. Second, it shows that the sperm collection success rate declined as birds were trapped closer to the day the first egg was laid in their nest $\left(\chi^{2}=13.5, \mathrm{df}=1, p=0.0002\right)$. Consequently, the period that optimizes sperm collection success seems to be comprised between 15 and 3 days before the laying of the first egg in the focal nest.

We further analyzed whether sperm collection success rate depended on the behaviour of the focal male/ pair just before catching the bird. We found that sperm collection success indeed depended on the behaviour of the birds (Fisher's exact test, $n=85, p=0.022$ ), with males trapped when they were about to mount their females being more likely to ejaculate semen containing live spermatozoa (Table 1). Other behaviours (female begging for food, after copulation or bird doing nothing) were unpredictive of our success to collect live sperm.

Table 1 Contingency table to test the independence between sperm collection success and the birds' behaviour

\begin{tabular}{|c|c|c|c|c|c|}
\hline & $\begin{array}{l}\text { No specific } \\
\text { behaviour }\end{array}$ & $\begin{array}{l}\text { Female begging } \\
\text { for food }\end{array}$ & Male about to mount & $\begin{array}{l}\text { Copulation occurred } \\
\text { recently }\end{array}$ & Row totals \\
\hline Successful collection & $\begin{array}{l}19 \\
22.4 \% \\
24.8 \%\end{array}$ & $\begin{array}{l}5 \\
5.9 \% \\
5.4 \%\end{array}$ & $\begin{array}{l}4 \\
4.7 \% \\
1.6 \%\end{array}$ & $\begin{array}{l}0 \\
0 \% \\
1 \%\end{array}$ & 28 \\
\hline Unsuccessful collection & $\begin{array}{l}45 \\
52.9 \% \\
50.5 \%\end{array}$ & $\begin{array}{l}9 \\
10.6 \% \\
11 \%\end{array}$ & $\begin{array}{l}0 \\
0 \% \\
3.2 \%\end{array}$ & $\begin{array}{l}3 \\
3.5 \% \\
2.3 \%\end{array}$ & 57 \\
\hline Column totals & 64 & 14 & 4 & 3 & 85 \\
\hline
\end{tabular}

Number, observed percentage and expected percentage (in italic) under $H_{0}$ (independence between sperm collection success and the birds' behaviour) for successful ( $\geq 10$ viable sperm in the ejaculate) and unsuccessful sperm collection according to the pair's behaviour immediately before male capture 


\section{Sperm survival: comparison of undiluted sperm and extenders}

We found that the survival of sperm diluted in PBS was always lower than in any other condition (diluted in extender or undiluted sperm; median survival, mean survival \pm SE; PBS: $29 \min 20 \mathrm{~s}, 28 \mathrm{~min} 46 \mathrm{~s} \pm 3 \mathrm{~min}$ $15 \mathrm{~s}$; Alternative condition: $39 \mathrm{~min}, 40 \mathrm{~min} 3 \mathrm{~s} \pm 5 \mathrm{~min}$ $5 \mathrm{~s} ; W=0, n=6, p<0.05)$. When sperm were diluted in DMEM and EBSS, spermatozoa survived longer than in any other condition (median, mean \pm SE; DMEM: 53 min $1 \mathrm{~s}, 43 \mathrm{~min} 40 \mathrm{~s} \pm 5 \mathrm{~min} 10 \mathrm{~s}$; Alternative buffer: $40 \mathrm{~min}$ $40 \mathrm{~s}, 39 \min 20 \mathrm{~s} \pm 4 \min 45 \mathrm{~s} ; W=8, n=9, p<0.05$ and EBSS: $41 \mathrm{~min} 40 \mathrm{~s}, 38 \mathrm{~min} 38 \mathrm{~s} \pm 4 \mathrm{~min} 20 \mathrm{~s}$; Alternative buffer: $31 \mathrm{~min} 10 \mathrm{~s}, 35 \mathrm{~min} 39 \mathrm{~s} \pm 4 \min 46 \mathrm{~s} ; W=8$, $n=9, p<0.05)$. Sperm diluted in $\mathrm{NaCl}$ did not survive significantly longer than in any other condition (median, mean \pm SE; NaCL: $52 \min 13 \mathrm{~s}, 51 \min 15 \mathrm{~s} \pm 2 \min 25 \mathrm{~s}$; Alternative buffer: $53 \mathrm{~min} 25 \mathrm{~s}, 47 \mathrm{~min} 29 \mathrm{~s} \pm 6 \mathrm{~min} 11 \mathrm{~s}$; $W=9, n=6, p>0.05)$. Undiluted sperm did not survive significantly longer than in any extender (median, mean \pm SE; No buffer: 27 min $6 \mathrm{~s}, 29$ min $26 \mathrm{~s} \pm 4$ min $20 \mathrm{~s}$; Alternative buffer: $28 \mathrm{~min} 37 \mathrm{~s}, 32 \mathrm{~min} 2 \mathrm{~s} \pm 4 \mathrm{~min}$ $35 \mathrm{~s} ; W=10, n=8, p>0.05)$. When excluding samples diluted in PBS, the survival of undiluted sperm or sperm diluted in DMEM, EBSS, or $\mathrm{NaCl}$ was on average 40 min $7 \mathrm{~s} \pm 2 \mathrm{~min} 33 \mathrm{~s}$, and the median survival was $41 \mathrm{~min} 40 \mathrm{~s}$ $(n=32)$. Table 2 shows the full data for comparison of sperm survival according to various pairwise combinations of preservation conditions.

\section{Sperm swimming ability and sperm morphology}

Mean values for sperm swimming traits and sperm morphological traits are provided in Table 3. Figure 4 illustrates the range of mean $( \pm S D)$ sperm total length and mean length of sperm components across males.

\section{Discussion}

In this study, we demonstrate for the first time that it is possible to collect live sperm in a non-destructive manner and under field conditions from a seabird. We were able to keep the spermatozoa from 19 ejaculates alive for at least $20 \mathrm{~min}$ at $40{ }^{\circ} \mathrm{C}$ when using the proper extender. Our results suggest that two semen extenders are suitable for maintaining sperm alive: Earle's balanced salt solution (EBSS) and Dulbecco modified Eagle's medium (DMEM). Yet, we recommend using the DMEM extender, because, although it requires to be stored at low temperature until use, it is cheaper than EBSS. Undiluted sperm also performed well in terms of survival, and it could be argued that the seminal fluid alone should be sufficient to maintain sperm alive for long enough to perform sperm quality analyses. It can
Table 2 Sperm survival (seconds) for ejaculates kept under two different conditions

\begin{tabular}{lllll}
\hline Bird ID & Condition 1 & Condition 2 & Survival 1 & Survival 2 \\
\hline KOC1634 & DMEM & Undiluted & 1640 & 2186 \\
KOC1614 & DMEM & EBSS & 3300 & 3125 \\
KOC1640 & NaCl & DMEM & 3210 & 3568 \\
KOC1637 & NaCl & DMEM & 3150 & 3360 \\
KOC1628 & Undiluted & PBS & 1395 & 1360 \\
KOC1630 & Undiluted & NaCl & 3310 & 3600 \\
KOC1614 & Undiluted & DMEM & 1565 & 2411 \\
KOC1635 & Undiluted & EBSS & 1687 & 1864 \\
KOC1647 & Undiluted & DMEM & 1207 & 1558 \\
KOC1649 & Undiluted & EBSS & 912 & 1145 \\
KOC1614 & PBS & EBSS & 1870 & 2182 \\
KOC1638 & PBS & Undiluted & 1794 & 1866 \\
KOC1640 & PBS & DMEM & 2500 & 3360 \\
KOC1640 & PBS & NaCl & 1104 & 3116 \\
KOC1630 & PBS & EBSS & 1725 & 2500 \\
KOC1640 & EBSS & NaCl & 2649 & 2575 \\
KOC1612 & EBSS & DMEM & 1200 & 1200 \\
KOC1640 & EBSS & DMEM & 3100 & 3181 \\
KOC1624 & EBSS & NaCl & 3100 & 2800 \\
\hline
\end{tabular}

also be argued that sperm extenders are unlikely to reflect the natural environment that sperm are going to encounter in the female reproductive tract. However, we still rencommend using a sperm extender for two reasons: (1) the use of such an extender is necessary to dilute some highly concentrated ejaculates and (2) in vitro CASA assays may provide valuable information on sperm quality, especially when comparing experimental groups or when investigating how environmental factors (e.g. pollutants) affect sperm production.

Computer assisted sperm analyses (CASA) are very powerful tools to assess parameters linked to sperm quality (Amann and Waberski 2014). Such parameters are usually the percentage of motile sperm, sperm swimming velocity (i.e. straightline velocity VSL, curvilinear velocity VCL or averaged path velocity VAP in $\mu \mathrm{m} / \mathrm{s}$ ), the linearity of the sperm trajectory, or sperm progressivity (a measure of efficiency in terms of proportion of motion resulting in movement away from the origin; Wilson-Leedy and Ingermann 2007; Amann and Waberski 2014). Several of these parameters, either alone or as a composite index of sperm quality obtained from principal component analyses, have been shown to be good proxies of sperm fertilizing ability in several species (Snook 2005; Simmons and Fitzpatrick 2012). Achieving the appropriate spermatozoa concentration is crucial when conducting CASA. When the sample is too dense, sperm trajectories cross and sperm cells 


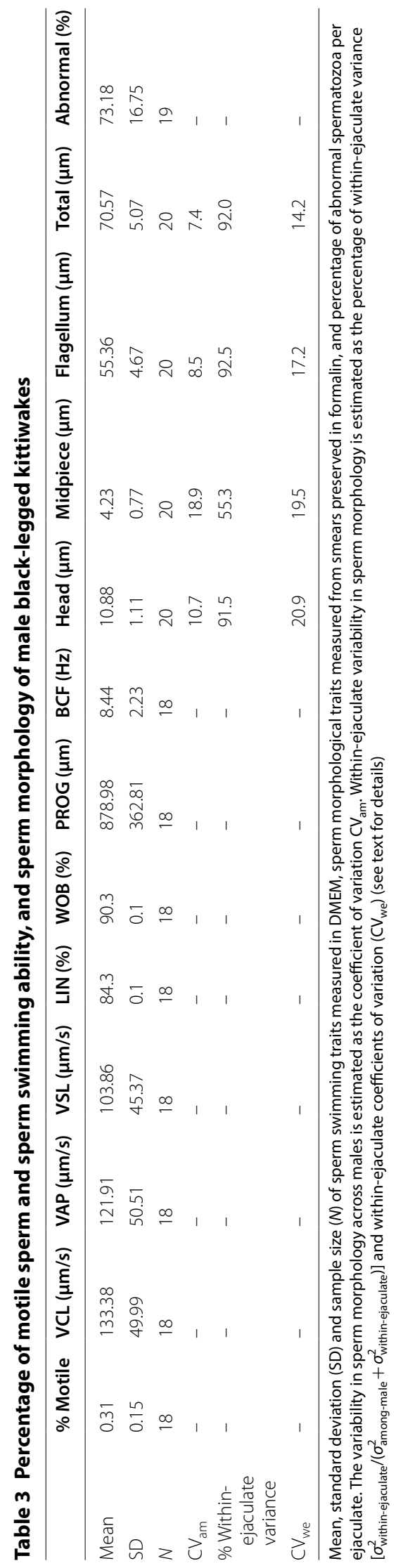



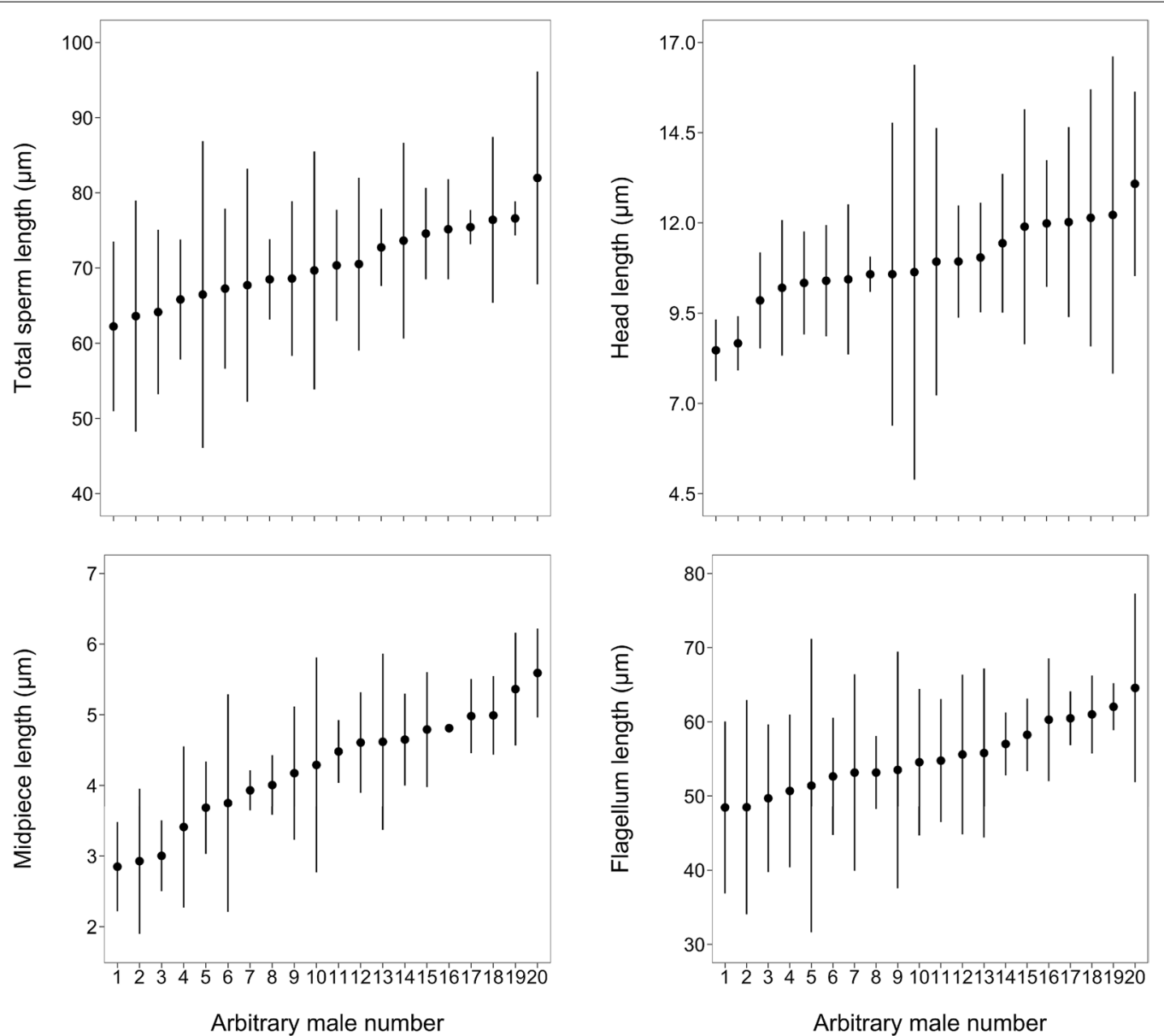

Fig. 4 Within- and between-male variance in sperm morphological traits based on 7-16 sperm cells (mean \pm SE: 10.1 \pm 0.5 ) for each of 20 males. Dots represent individual mean lengths $( \pm S D$ ) ranked in order of magnitude

bump into each other, resulting in biased estimations of the aforementioned parameters (Wilson-Leedy and Ingermann 2007). We thus recommend always using a sperm extender to control, and if necessary adjust, the density of the sample to be analysed.

Apart from the addition of a sperm extender, field conditions preclude any sample preparation, and sperm samples cannot be washed and cleaned from unwanted cells or debris. The presence of such cells or debris in sperm samples may compromise the accuracy of the measures performed by the CASA plugin. Here, most particles were removed using the threshold function in ImageJ and by setting a range of size (in pixels) for sperm cells. Yet, we are aware that not all particles could be removed this way. However, this should not affect the estimation of sperm speed or rectitude in sperm trajectory, because immotile particles or particles moved by drift having a size within that of a sperm cell were excluded from the analysis by our criteria on
VCL and VAP (see "Methods" section). Nevertheless, it should be noted that such particles lead to underestimating the percentage of motile sperm.

Interestingly, the period when our success rate in collecting sperm was highest, 25 to 6 days before laying, only partly overlaps the peak of copulations reached within the 15 days that precede laying (Helfenstein et al. 2004). Since higher copulation frequency during the 15 days preceding laying may result in lower sperm collection success (see Table 2) due to sperm depletion, we recommend starting sperm collection three weeks before the first egg is usually laid in the colony. This should provide enough time to the researchers to repeatedly capture and massage a large number of males. Nevertheless, one has to keep in mind that sperm quality may vary seasonally, and we recommend to statistically account for this effect using the date relative to laying. In addition to targeting a specific time window, we suggest to target birds about to copulate, i.e. when 
the male is about to mount the female, and avoid catching birds that already copulated within the day.

We found that ejaculates contain on average $73.18 \%$ of abnormal sperm and between 55 and $92 \%$ of the total variance in sperm size and size of sperm components are attributable to variation in morphology within ejaculates rather than between males (Table 3; Fig. 4). These figures are much higher than results of previous studies in wild birds (e.g. Calhim et al. 2007; Laskemoen et al. 2007; Helfenstein et al. 2010; Calhim et al. 2011; Rakha et al. 2015), and they deserve an explanation. First, it could be argued that smearing the spermatozoa on a glass slide may damage the cells and artificially inflate the percentage of abnormal sperm and within-ejaculate variation in sperm morphology. Yet, this method has been used by the authors and other researchers in a variety of bird species (e.g. Calhim et al. 2007; Laskemoen et al. 2007; Helfenstein et al. 2010; Rakha et al. 2015), and such high values of sperm abnormality or within-ejaculate variation in sperm morphology in a wild, free-ranging bird are unusual. Studies conducted on populations of several bird species living around Chernobyl have reported high levels of sperm abnormality, but those values are likely caused by high levels of ionizing radiations increasing mutation rates (Møller et al. 2005; Hermosell et al. 2013). Alternatively, it has been suggested that both inter-male and intra-male/ejaculate variation in sperm morphology may be explained by variation in the strength of post-copulatory sexual selection, particularly sperm competition (Calhim et al. 2007; Kleven et al. 2008). Indeed, van der Horst and Maree (2014) examined the literature and showed that vertebrate species with no sperm competition or extremely low risk of sperm competition exhibit high within-ejaculate variation in sperm morphology and high percentage of abnormal sperm. In birds, Eurasian (Pyrrhula pyrrhula) and Azores Bullfinches (Pyrrhula murina) produce spermatozoa with an atypical morphology compared to other Passeriformes and their ejaculates are characterized by great variation in sperm mophology and high percentage of abnormal sperm (Birkhead et al. 2006, 2007; Lifjeld et al. 2013). Such characteristics have been interpreted as a consequence of an absence of sperm competition (Birkhead et al. 2006, 2007; Lifjeld et al. 2013). Here, we found a high percentage of abnormal sperm, large proportions of within-ejaculate variance and large within-ejaculate coefficients of variation in sperm morphology (Table 3). These results accord well with the hypothesis of relaxed selection and lack of sperm competition, as Black-legged Kittiwakes are known to be strictly monogamous (Helfenstein et al. 2004).

\section{Conclusions}

Unlike passerines birds who store their semen in the seminal glomera (Lake 1981), Black-legged Kittiwakes store their semen inside their body (Lake 1981), thus preventing direct stimulation of the storage organs. Furthermore, these birds are strictly monogamous (Helfenstein et al. 2004), and are likely selected to produce small quantities of sperm during a short period. Nevertheless, we have been able to trap 25 males and obtain as many ejaculates within 2 weeks. We thus believe that larger samples can be aimed for not only in kittiwakes, but in seabirds with similar ecology and exhibiting some levels of extrapair paternity such as other larids (e.g. the Blackheaded Gull Larus ridibundus; Ležalová-Piálková 2011, or Common Gull Larus canus; Bukacińska et al. 1998) or alcids (Wagner 1992) where males are expected to produce larger amounts of sperm (Møller and Briskie 1995).

\section{Additional files}

Additional file 1. Video showing sperm collection on a Black-legged Kittiwake.

Additional file 2. Video of spermatozoa in motion.

Additional file 3. We checked the minimum number of sperm cells per ejaculate required for accurate estimates of ejaculate mean and standard deviation using a resampling procedure. We randomly sampled 1 to 15 sperm cells per ejaculate without replacement and computed the associated mean (Fig. S1) and standard deviation (Fig. S2). A visual assessment of the plots reveals that a minimum of 10 sperm cells per ejaculate allows accurate estimates of mean and SD.

Additional file 4. Additional dataset.

Authors' contributions

SHG, OC, PB, and GWG participated in the design of the study and its coordination. SHG, PB and OC collected the data in the field. AY and $A A B$ analysed sperm samples. SHG and FH carried out the statistical analyses. SHG and FH wrote the manuscript. All authors read and approved the final manuscript.

\section{Author details}

${ }^{1}$ Laboratory of Evolutionary Ecophysiology, Institute of Biology, University of Neuchatel, Rue Emile-Argand 11, 2000 Neuchatel, Switzerland. ${ }^{2}$ Centre d'Etudes Biologiques de Chizé (CEBC), UMR 7372-CNRS, Université de La Rochelle, 79360 Villiers-en-Bois, France. ${ }^{3}$ Norwegian Polar Institute, Fram Centre, 9296 Tromsø, Norway.

\section{Acknowledgements}

We thank David Costantini and Bruno Michaud for great help in the field and the AWIPEV and Norwegian Polar Institute staffs for their great help with logistics.

\section{Competing interests}

The authors declare they have no competing interests.

\section{Availability of supporting data}

All data generated or analysed during this study are included in this published article and its supplementary information files.

Consent for publication

Not applicable. 


\section{Ethics approval}

This study was examined and approved by the Norwegian Animal Ethics Committee and the governor of Svalbard, and was conducted under permission FOTS ID 2738679

\section{Funding}

This project was supported by the Institut Polaire Français, IPEV project 330 to OC. PB was funded by an Arctic Field Grant (No. 256934) from the Research Council of Norway and by a Ph.D grant from University of La Rochelle. FH was financially supported by a grant from the Swiss National Science Foundation (No.PP00P3_139011).

Received: 11 February 2018 Accepted: 9 July 2018

Published online: 14 July 2018

\section{References}

Alberti G. Comparative spermatology of Araneae. Acta Zool Fennica. 1990;190:17-34.

Amann RP, Waberski D. Computer-assisted sperm analysis (CASA): capabilities and potential developments. Theriogenology. 2014;81(5-17):e3.

Barrett R. Adult body temperature and the development of endothermy in the kittiwake (Rissa tridactyla). Astarte. 1978;11:113-6.

Birkhead TR, Pizzari T. Postcopulatory sexual selection. Nat Rev Genet. 2002:3:262-73.

Birkhead TR, Immler S, Pellatt EJ, Freckleton R, Briskie JV. Unusual sperm morphology in the Eurasian bullfinch (Pyrrhula pyrrhula). Auk. 2006:123:383-92

Birkhead TR, Giusti F, Immler S, Jamieson BGM. Ultrastructure of the unusual spermatozoon of the Eurasian bullfinch (Pyrrhula pyrrhula). Acta Zool. 2007;88:119-28.

Brent R, Rasmussen J, Bech C, Martini S. Temperature dependence of ventilation and $\mathrm{O}_{2}$-extraction in the kittiwake, Rissa Tridactyla. Experientia. 1983;39:1092-3.

Bronson FH. Mammalian reproductive biology. Chicago: University of Chicago Press; 1989.

Bukacińska M, Bukaciński D, Epplen JT, Sauer KP, Lubjuhn T. Low frequency of extra-pair paternity in Common Gulls (Larus canus) as revealed by DNA fingerprinting. J Ornithol. 1998;139:413-20.

Calhim S, Immler S, Birkhead TR. Postcopulatory sexual selection is associated with reduced variation in sperm morphology. PLoS ONE. 2007;2:e413.

Calhim S, Double MC, Margraf N, Birkhead TR, Cockburn A. Maintenance of sperm variation in a highly promiscuous wild bird. PLoS ONE. 2011;6:e28809.

Coulson J. The kittiwake. London:T \& AD Poyser; 2011

Eberhard WG. Female control: sexual selection by cryptic female choice. Princeton: University Press; 1996.

Elliott JE, Elliott KH. Tracking marine pollution. Science. 2013;340:556

Fitzpatrick JL, Lüpold S. Sexual selection and the evolution of sperm quality. Mol Human Reprod. 2014;20:1180-9.

Franzén A. On spermiogenesis, morphology of the spermatozoon, and biology of fertilization among invertebrates. Zoologiska Bidrag Från Uppsala. 1956;31:355-482

Goutte A, Clément-Chastel C, Moe B, Bech C, Gabrielsen GW, Chastel O. Experimentally reduced corticosterone release promotes early breeding in black-legged kittiwakes. J Exp Biol. 2011;214:2005-13.

Hatef A, Alavi SMH, Golshan M, Linhart O. Toxicity of environmental contaminants to fish spermatozoa function in vitro: a review. Aquat Toxicol. 2013:140-141:134-44

Helfenstein F, Tirard C, Danchin E, Wagner RH. Low frequency of extra-pair paternity and high frequency of adoption in black-legged kittiwakes. Condor. 2004;106:149-55.

Helfenstein F, Podevin M, Richner H. Sperm morphology, swimming velocity, and longevity in the house sparrow Passer domesticus. Behav Ecol Sociobiol. 2010;64:557-65.

Hermosell IG, Laskemoen T, Rowe M, Møller AP, Mousseau TA, Albrecht T, Lifjeld JT. Patterns of sperm damage in Chernobyl passerine birds suggest a trade-off between sperm length and integrity. Biol Lett. 2013;9:20130530.
Jamieson BGM. Avian spermatozoa: structure and phylogeny. In: Jamieson BGM, editor. Reproductive biology and phylogeny of birds, vol 6A, B. Enfield: Science Publishers; 2007. p. 349-511.

Jurewicz J, Hanke W, Radwan M, Bonde J. Environmental factors and semen quality. Int J Occup Med Environ Health. 2009;22:305-29.

Kleven O, Laskemoen T, Fossøy F, Robertson RJ, Lifjeld JT. Intraspecific variation in sperm length is negatively related to sperm competition in passerine birds. Evolution. 2008;62:494-9.

Komsky-Elbaz A, Roth Z. Effect of the herbicide atrazine and its metabolite DACT on bovine sperm quality. Reprod Toxicol. 2017;67:15-25.

Lafuente R, Garcia-Blaquez N, Jacquemin B, Checa MA. Outdoor air pollution and sperm quality. Fertil Steril. 2016;106:880-96.

Lake P. Male genital organs. In: King AS, McLelland J, editors. Form and function in birds, vol. 2. London: Academic Press; 1981. p. 1-62.

Laskemoen T, Kleven O, Fossoy F, Lifjeld JT. Intraspecific variation in sperm length in two passerine species, the Bluethroat Luscinia svecica and the Willow Warbler Phylloscopus trochilus. Ornis Fennica. 2007;84:131-9.

Ležalová-Piálková R. Molecular evidence for extra-pair paternity and intraspecific brood parasitism in the black-headed Gull. J Ornithol. 2011;152:291-5.

Lifjeld JT, Hoenen A, Johannessen LE, Laskemoen T, Lopes RJ, Rodrigues P, Rowe M. The Azores bullfinch (Pyrrhula murina) has the same unusual and size-variable sperm morphology as the Eurasian bullfinch (Pyrrhula pyrrhula). Biol J Linn Soc. 2013;108:677-87.

Merkling T, Blanchard P, Chastel O, Glauser G, Vallat-Michel A, Hatch SA, Danchin E, Helfenstein F. Reproductive effort and oxidative stress: effects of offspring sex and number on the physiological state of a long-lived bird. Funct Ecol. 2017;31:1201-9.

Møller AP, Briskie JV. Extra-pair paternity, sperm competition and the evolution of testis size in birds. Behav Ecol Sociobiol. 1995;36:357-65.

Møller AP, Surai PF, Mousseau TA. Antioxidants, radiation and mutation as revealed by sperm abnormality in barn swallows from Chernobyl. Proc $\mathrm{R}$ Soc B. 2005:272:247-52

Nicopoullos JDM, Almeida PA, Ramsay JWA, Gilling-Smith C. The effect of human immunodeficiency virus on sperm parameters and the outcome of intrauterine insemination following sperm washing. Hum Reprod. 2004; 19:2289-97.

O'Brien J, Oehler D, Malowski S, Roth T. Semen collection, characterization, and cryopreservation in a Magellanic penguin (Spheniscus magellanicus). Zoo Biol. 1999:18:199-214.

Parker GA. Sperm competition and its evolutionary consequences in the insects. Biol Rev. 1970:45:525-67.

Pitnick S, Hosken DJ, Birkhead TR. Sperm morphological diversity. In: Birkhead TR, Hosken DJ, Pitnick S, editors. Sperm biology: an evolutionary perspective. Oxford: Academic Press; 2009. p. 71-149.

Reinhardt K, Dobler R, Abbott J. An ecology of sperm: sperm diversification by natural selection. Annu Rev Ecol Evol Syst. 2015:46:435-59.

Rakha BA, Ansari MS, Hussain I, Malik MF, Akhter S, Blesbois E. Semen characteristics of the Indian Red Jungle Fowl (Gallus gallus murghi). Eur J Wild Res. 2015;61:379-86.

Schneider CA, Rasband WS, Eliceiri KW. NIH Image to ImageJ: 25 years of image analysis. Nat Methods. 2012;9:671-5.

Sharpe RM. Environmental/lifestyle effects on spermatogenesis. Philos Trans R Soc Lond B Biol Sci. 2010;365:1697-712.

Simmons LW, Fitzpatrick JL. Sperm wars and the evolution of male fertility. Reproduction. 2012;144:519-34.

Snook RR. Sperm in competition: not playing by the numbers. Trends Ecol Evol. 2005:20:46-53.

Sokal RR, Rohlf JF. Biometry. New York: W. H. Freeman; 1995.

Swan SH, Kruse RL, Liu F, Barr DB, Drobnis EZ, Redmon JB, Wang C, Brazil C, Overstreet JW. Semen quality in relation to biomarkers of pesticide exposure. Environ Health Perspect. 2003;111:1478-84.

Thornhill R. Cryptic female choice and its implications in the Scorpionfly Harpobittacus nigriceps. Am Nat. 1983;122:765-88.

van der Horst G, Maree L. Sperm form and function in the absence of sperm competition. Mol Reprod Dev. 2014:81:204-16.

Wagner $\mathrm{RH}$. The pursuit of extra-pair copulations by monogamous female razorbills: how do females benefit? Behav Ecol Sociobiol. 1992;29:455-64

Wilson-Leedy JG, Ingermann RL. Development of a novel CASA system based on open source software for characterization of zebrafish sperm motility parameters. Theriogenology. 2007;67:661-72. 
Wilson RP, Liebsch N, Davies IM, Quintana F, Weimerskirch H, Storch S, Lucke K, Siebert U, Zankl S, Müller G, Zimmer I, Scolaro A, Campagna C, Plötz J, Bornemann H, Teilmann J, McMahon CR. All at sea with animal tracks; methodological and analytical solutions for the resolution of movement. Deep Sea Res Part 2 Top Stud Oceanogr. 2007:54:193-210.

- fast, convenient online submission

- thorough peer review by experienced researchers in your field

- rapid publication on acceptance

- support for research data, including large and complex data types

- gold Open Access which fosters wider collaboration and increased citations

- maximum visibility for your research: over 100M website views per year

At $\mathrm{BMC}$, research is always in progress.

Learn more biomedcentral.com/submissions 